\title{
A CONSTRUÇÃO DO INDICADOR DE DENSIDADE, VERTICALIDADE E SUSTENTABILIDADE (IDVS) PARA CONDOMÍNIOS Estudo de caso no município de Campo Grande/MS
}

\author{
Autor: TORRES, L. A., ALMEIDA, L. C. B., ARRUDA, A. M. V. \\ Universidade: Universidade Federal do Mato Grosso do Sul, Universidade Federal de Santa Catarina \\ E-mail: arqltorres@gmail.com, laiscarolinealmeida@gmail.com, angelomv@uol.com.br.
}

\begin{abstract}
RESUMO
O trabalho apresenta o estudo para a construção do Indicador de Densidade, Verticalidade e Sustentabilidade Urbana (IDVS) para condomínios verticais no município de Campo Grande, no estado do Mato Grosso do Sul, Brasil. Desenvolvido com a finalidade de encontrar um indicador ideal de moradia com qualidade no espaço público e privado dos condomínios. Foram desenvolvidas pesquisas dentro dos aspectos de densidade, verticalidade e sustentabilidade estabelecendo parâmetros indicados por profissionais da área (arquitetos urbanistas, professores, pesquisadores e construtores) que estabeleceram pesos distintos entre os itens levantados. As variáveis escolhidas se dividem em 10 itens para "fora do condomínio" e 10 para "dentro do condomínio".
\end{abstract}

Palavras-chave: Indicador. Densidade. Verticalidade. Sustentabilidade.

\begin{abstract}
The study presents the study for the construction of the Density, Verticality and Urban Sustainability Indicator (IDVS) for vertical condominiums in the municipality of Campo Grande, in the state of Mato Grosso do Sul, Brazil. Developed with the purpose of finding an ideal indicator of housing with quality in the public space and private condominiums. Researches were developed within the density, verticality and sustainability aspects, establishing parameters indicated by area professionals (urban planners, teachers, researchers and builders) who established different weights among the items surveyed. The variables chosen are divided into 10 items for "outside the condominium" and 10 for "inside the condominium".'
\end{abstract}

Key words: Indicator. Density. Verticality. Sustainability. 


\section{INTRODUÇÃO}

Nas discussões sobre cidades sustentáveis tem surgido a necessidade de criar indicadores de sustentabilidade tanto para a cidade como para o espaço construído, para que possam contribuir nas decisões de planejadores, arquitetos, construtores e responder as expectativas dos citadinos e melhorar a qualidade de vida nas cidades.

Este estudo resultou na elaboração do IDVS, um indicador de densidade, verticalidade e sustentabilidade urbana na cidade de Campo Grande, no estado de Mato Grosso do Sul, Brasil. Foi elaborado a partir dos estudos sobre os temas no Observatório de Arquitetura e Urbanismo da Universidade Federal de Mato Grosso do Sul - UFMS. Percebendo que ao analisar a cidade é importante a integração e a multidisciplinaridade para a geração das variáveis e de resultados do indicador. Integrando os conceitos de cidade sustentáveis, densidade e verticalidade resultaram na criação de um indicador abrangendo esses três conceitos com o objetivo de responder questões complexas do espaço urbano e do ambiente construído e sua relação com seus habitantes e a natureza. Esse indicador é uma proposta metodológica que pode ser utilizada como um método por outros pesquisadores ou usuários.

As pesquisas teóricas para promover o conhecimento do tema - densidade e verticalização com sustentabilidade - observou os pioneiros nessa discussão, especialmente Le Corbusier e Jane Jacobs, Mascaró, Accioly, mais recentemente, Jan Gehl. Ou seja, há referenciais teóricos para analisar e contextualizar a cidade no mundo, a suas origens na verticalização e o adensamento.

As primeiras impressões sobre o conceito de sustentabilidade iniciaram-se no ano de 1972, através de reuniões de alguns intelectuais que entendiam e se preocuparam pelas questões ambientais, política, economia internacional e desenvolvimento sustentável. (Vargas, 2002)

No Brasil, esse tema teve início através da Conferência das Nações Unidas a respeito do meio ambiente e desenvolvimento (CNUCED), que aconteceu no Rio de Janeiro no ano de 1992, onde ficou conhecida como a RIO-92 ou ECO-92. Nesta conferência participavam pesquisadores, chefes de Estado e representantes da sociedade organizada de 179 países, com um total de aproximadamente 35 mil pessoas presentes, para as discussões relacionadas ao meio ambiente e desenvolvimento sustentável para o século XXI. A grande discussão perpetuou nas críticas sobre os perigos do modelo de desenvolvimento retratado na população mundial, com isso, buscou-se a criação de um documento representado como um acordo internacional das ações que buscaram melhorar a qualidade de vida das pessoas e meio ambiente como um todo, apresentado como Agenda $21^{1}$.

A Agenda 21 salientou a importância de um desenvolvimento sustentável, de acordo com a Declaração da Conferência de Estocolmo (1972), onde apresentavam propostas de novos conceitos e instrumentos metodológicos para um leque de ações e investigações que tinham como base a relação entre o ser humano e o meio ambiente. (Santos, 1999)

O pensamento da construção de cidades sustentáveis surgiu por meio dessas reuniões intelectuais discutidas a respeito da sustentabilidade (por volta dos anos 70 ). A cidade sustentável busca a aplicação de boas práticas no meio urbano, com o incentivo do uso de materiais menos poluentes, transporte público de qualidade, uso do solo de forma eficiente e qualidade de vida das pessoas.

Roger-Machart, citado por Magalhães (2006) afirma: "uma cidade sustentável é a que preenche as necessidades de seus atuais cidadãos, sem esgotar os recursos das futuras gerações de todo o mundo (...) recursos de maximização da eficiência do uso dos recursos". (Magalhães, 2006)

Para Jacobs estudar a cidade corresponde a entender que:

"As cidades são um imenso laboratório de tentativa e erro, fracasso e sucesso, em termos de construção e desenho urbano. É nesse laboratório que o planejamento urbano deveria aprender, elaborar e testar suas teorias. Ao contrário, os especialistas e os professores dessa disciplina (se é que ela pode ser assim chamada) têm ignorado o estudo do sucesso e do fracasso na vida real, não tem tido curiosidade a respeito das razões do sucesso inesperado e pautam-se por princípios derivados do comportamento e da aparência de cidades e bairros e cidades imaginárias perfeitas, qualquer coisa que não as cidades reais". Jane Jacobs, 1961

Por meio dos estudos teóricos, analisando o pensamento de diversos autores nacionais e internacionais, foi possível analisar aspectos de potenciais e de condições como um caminho no qual possa seguir para nortear os estudos para a elaboração de um indicador de densidade, verticalidade e sustentabilidade.

\footnotetext{
${ }^{1}$ A Agenda 21 é um documento assinado em 14 de junho de 1992, no Rio de Janeiro, por 179 países, resultado da "Conferência das Nações Unidas sobre Meio Ambiente e Desenvolvimento" - Rio 92, podendo ser definida como um "instrumento de planejamento participativo visando o desenvolvimento sustentável".
} 


\section{OBJETIVO}

A densidade, a verticalização e a sustentabilidade urbana são atualmente, questões que estão caminhando juntas em busca de uma alternativa para a cidade sustentável. Para que se tenha uma cidade sustentável, é necessário encontrar a densidade urbana ideal para a cidade, considerando diversos aspectos teóricos e específicos do município. Qual é a densidade ideal? Como a verticalidade pode influenciar na qualidade de vida na cidade? Como promover a sustentabilidade na arquitetura e na cidade ao mesmo tempo? Essas perguntas precisam ser respondidas, examinando, sempre, o contexto urbano e todas as possibilidades urbanas para que se possa compreender a forma de produção e reprodução da cidade.

A densidade urbana, portanto, é uma das variáveis mais importante para a sustentabilidade urbana. Podemos pensar em densidade urbana controlada, limitada, inclusiva, mas devemos refletir nas questões da verticalidade e nos aspectos construtivos e urbanos e estudar propostas que possam contribuir com 0 equilíbrio do desenvolvimento urbano e humano.

Assim esse trabalho tem como objetivo elaborar um indicador de sustentabilidade em condomínios horizontais e verticais, o IDVS, para contribuir na produção do espaço urbano, nos projetos de construção e na avaliação dos aspectos essenciais para os empreendimentos arquitetônicos e urbanos, tendo a cidade de Campo Grande como estudo para esse indicador.

\section{CONSTRUÇÃO DO IDVS}

A cidade sustentável, atualmente é defendida como uma cidade humana e equilibrada, onde as atividades diárias, como emprego, escola e alimentação estão próximas, assim como também são atendidas de forma adequada as questões de saneamento, segurança e cultura.

Leite (2012) defende que uma cidade sustentável deve atender os quesitos sociais, ambientais, políticos e culturais, como também os objetivos econômicos e físicos dos seus habitantes. Essas características estão extremamente ligadas com a chamada cidade compacta, onde se conceitua com a concentração do uso e ocupação do solo misto planejado de forma equilibrada e com densidades urbanas altas, ou seja, um adequado e planejado uso do solo urbano, misturando funções urbanas (habitação, comércio, serviços, lazer, etc.) de forma eficiente, em conjunto com um sistema de mobilidade urbana que gere conexão qualificada do transporte público, e consequentemente o incentivo ao uso do modal a pé e de bicicleta.

Rogers (2000) defende a cidade compacta como a cidade ideal devido as suas características sustentáveis, com moradias em forma de comunidade, ele alega que a cidade tem que ser próxima e vivida por seus habitantes, proporcionando conectividade e qualidade de vida. A figura 1 apresenta esquematicamente 0 modelo de planejamento urbano compacto.

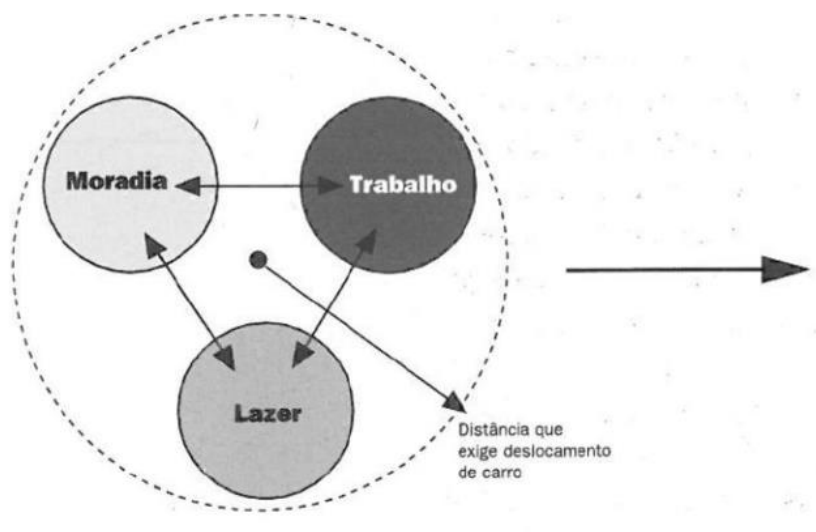

O zoneamento das atividades induz à utilização e dependência do automóvel particular.

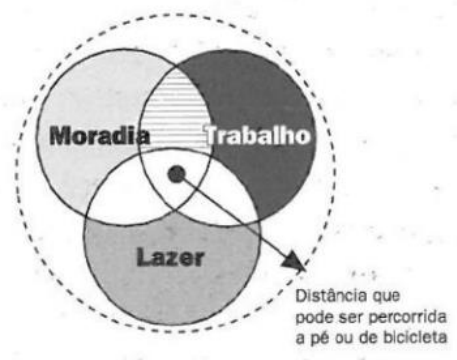

Núcleos compactos reduzem as distâncias e permitem o deslocamento a pé ou de bicicleta.

Figura 1 - Esquema de cidade compacta (Rogers, 2000)

O modelo esquemático da sustentabilidade urbana pode ser apresentado com alguns pilares que fundamentam e estrutura a sustentabilidade de uma cidade, Leite (2012) destaca os seguintes eixos para a sustentabilidade urbana eficaz: 
Tabela 1 - Temas definidores para indicadores de sustentabilidade urbana

\begin{tabular}{|l|}
\multicolumn{1}{|c|}{ Eixos para indicadores de Sustentabilidade Urbana } \\
\hline 1- Construção e infraestrutura sustentáveis \\
\hline 2 - Governança \\
\hline 3 - Mobilidade \\
\hline 4 - Moradia \\
\hline 5 - Planejamento e ordenamento territorial \\
\hline 6 - Questões ambientais \\
\hline 7 - Segurança \\
\hline 8 - Serviços e equipamentos \\
\hline 9 - Oportunidades \\
(Leite, 2012)
\end{tabular}

Leite (2012) apresenta também alguns aspectos que estão totalmente ligados a cidade sustentável e compacta, e que são fatores primordiais para a implantação deste conceito nas cidades, nos quais são: densidade qualificada, necessidades urbanas básicas eficientes, interação social, solução dos déficits habitacionais e da falta de diversidade socioterritorial e crescimento ordenado do território.

Segundo o autor: "A cidade sustentável baseia-se em um modelo de desenvolvimento urbano que promove, relativamente, altas densidades de modo qualificado, ou seja, com adequado e planejado uso misto do solo, misturando funções urbanas (habitação, comércio e serviços)" (Leite, 2012).

Os argumentos em favor de cidades compactas, com alto grau de adensamento, opondo-se aos processos de espraiamento e baixas densidades relativas presentes na urbanização dispersa têm levantado questões relativas às densidades urbanas que nem sempre são expressas com a clareza necessária. Por outro lado, definições de densidades urbanas estão usualmente associadas a recomendações normativas em regulamentações urbanísticas, notadamente na definição de índices urbanísticos presentes no zoneamento de uso e ocupação do solo. O que está implícito nesses dois casos é o estabelecimento de máximos e mínimos de adensamento, implicando, em seu limite, a esperança de estabelecer uma densidade ótima com validade senão universal, pelo menos aplicável de modo generalizado em função da capacidade das infraestruturas, em particular as de transportes. Em um contexto ampliado, trata-se das temáticas complementares e simultâneas do congestionamento de partes de cidades - notadamente suas áreas centrais - e da expansão descontínua e desigual da urbanização por extensas porções de território, temáticas que têm dominado o processo de urbanização e o imaginário de urbanistas e planejadores desde meados do século XIX (Secchi, 2006 e 2009 in Rivera de Castro, 2016).

Arza Churchman, analisando as aplicações e tribulações do conceito de densidades, apresentou as seguintes pautas:

- As medidas de densidade devem ser claramente explicitadas, bem como os objetivos com que são empregadas;

- A complexidade do mundo real e as inter-relações entre as múltiplas variáveis presentes no estabelecimento de densidades devem ser claramente explicitadas;

- Essa complexidade inclui as densidades percebidas - a percepção de densidades - pelos inúmeros atores sociais, em particular pelos gestores e planejadores;

- Não há uma solução única (ou em outras palavras, uma densidade ótima), mas uma variedade de soluções de assentamentos, vizinhanças, habitação e transportes, baseados em configurações específicas de necessidades e expectativas;

- Muito mais pesquisa é necessária em relação "aos vários aspectos e ramificações de diferentes tipos e níveis de densidade, em particular "as relações entre densidade objetiva, densidade percebida, e as avaliações positivas e negativas" (Churchman, 1999, p. 407-408).

No Relatório Final da Pesquisa "Vazios Urbanos em Campo Grande", Ermínia Maricato (2016) lembra-nos que "em que pesem as divergências entre urbanistas do mundo todo, há uma quase unanimidade na crítica à cidade dispersa". Ela reforça que "a extensão ampla e horizontal na ocupação do solo com baixa densidade, que tem nos subúrbios americanos o principal exemplo, é ambientalmente e economicamente insustentável".

Ao defender o modelo de "cidade compacta", Maricato nos lembra da cidade dispersa e orienta: 
- A cidade dispersa é a causa de viagens diárias mais longas sustentadas, principalmente, pelo veículo motorizado individual. O automóvel e o combustível fóssil, como sabemos, é um dos maiores promotores do aquecimento global e de doenças ocasionadas pela poluição do ar.

- Na cidade dispersa as redes de infraestrutura - água, coleta de esgotos, drenagem de águas pluviais, iluminação pública, pavimentação - também são mais estendidas e, portanto, mais caras no custo per capita. Tanto sua construção ou instalação, como sua manutenção, resultam menos econômicas. É preciso lembrar também que os serviços resultam mais caros. É o caso da coleta e destinação do lixo, serviços de educação e saúde, etc.

- Na cidade dispersa, pelos motivos apontados, os moradores passam mais tempo nos transportes, tempo que não é dedicado ao lazer, à família.

- A cidade dispersa, baseada no transporte rodoviário, resulta em maior superfície impermeabilizada impactando o meio ambiente.Grande parte do solo urbano é destinada às ruas e aos estacionamentos.

Jacobs (1961), nos lembra que é a mistura de uso das edificações que propicia uma cidade mais viva (e segura) durante o dia ou durante a noite. Sem dúvida a cidade viva está relacionada a certa densidade e também na diversidade de usos (moradia, serviços, comércio, lazer). Ela será culturalmente e socialmente mais rica, ou mesmo mais justa e segura, se apresentar diversidade de idades, de etnias e rendas. $O$ gueto, formado apenas por ricos ou pobres, ou por determinada característica social apresenta, frequentemente, o que podemos chamar de patologias urbanas e sociais.

Para Jabobs (1961), as densidades habitacionais são tão importantes para a maioria dos distritos urbanos e seu desenvolvimento futuro e tão raramente consideradas como fator de vitalidade. "As altas densidades são malvistas no urbanismo ortodoxo e na teoria do planejamento habitacional. Acredita-se que elas levam a toda espécie de dificuldade e ao insucesso", afirma ela.

Jacobs (1961) discute que grandes concentrações de pessoas são uma das condições necessárias para o florescimento da diversidade urbana. Sem número suficiente de pessoas essa diversidade não existe. $\mathrm{E}$ lembra: "Alta densidade urbana não é superpopulação. Alta densidade significa quantidade de pessoas por hectare. Superpopulação é excessiva quantidade de pessoas por domicílio".

Densidades urbanas adequadas são uma questão de funcionalidade. A densidade deve promover a adequada utilização dos recursos disponíveis e promover a diversidade do bairro. "Em suma, o meio é o melhor. Nem alta - acima de 1000 nem baixa, abaixo de 80 hab/ha. A diversidade funcional deve abarcar a diversidade das edificações" afirma Jabobs (1961).

Hoje sabemos que a proximidade de serviços e comércio no entorno das residências possibilita que uma parte das viagens seja feita a pé ou utilizando bicicletas e com isso as viagens motorizadas são eliminadas ou encurtadas e o ambiente construído resultará mais amigável aos idosos e crianças.

Para Cisneiros (2014) o adensamento urbano é bom e necessário e que as cidades podem funcionar melhor nesse seu objetivo de misturar gente se for possível colocar mais pessoas por hectare e também aproximar as diversas funções urbanas. Segundo o autor:

- Uma cidade mais compacta, menos espalhada, facilita não só ir de casa ao trabalho e ir de casa à padaria, mas também facilita encontrar os amigos pra uma conversa. $O$ adensamento permite mais interações planejadas ou espontâneas, embora não seja o único fator necessário para que isso aconteça.

- O adensamento, ao permitir agrupar mais pessoas em menos solo, permite, em tese, consumir menos terra e, por consequência, deixar mais parte do meio ambiente natural intocado.

- O adensamento causa economias com infraestrutura. Por exemplo, a rede viária é menor e atende mais pessoas. Se as pessoas começam a morar fora do centro urbano, em condomínios distantes, as necessidades de deslocamento serão maiores e os custos para prover essa infraestrutura serão maiores. $\mathrm{Na}$ verdade, o espraiamento pode até inviabilizar alguns serviços públicos como o de transporte público, pois o espraiamento cria longos trajetos com baixa demanda. O comércio e a ofertas de serviços privados também se prejudica pela baixa densidade, principalmente numa escala local: em uma área densa, o dono de um pequeno mercado consegue ter um número suficiente de potenciais consumidores num pequeno raio de deslocamento, que pode ser feito a pé ou de bicicleta. No meio de uma área residencial de condomínios na Zona Rural é possível que não existam mais de dez casas num raio de $500 \mathrm{~m}$, os pequenos mercados se tornem inviáveis e os moradores acabem se deslocando por carro para fazer compras semanais em hipermercados.

Por fim, densidade baixa demais prejudica a vitalidade urbana, o movimento de pessoas nas ruas, tornando-as mais desertas e perigosas. Mesmo em áreas urbanas, como notou Jane Jacobs, a densidade nas áreas vizinhas é uma das condições mais importantes para que parques sejam intensamente frequentados se tornem um sucesso.

Entretanto, Cisneiros (2014) ressalta que o oposto, ou seja, o adensamento excessivo vem com custos que devem ser contrapostos aos ganhos previstos, como por exemplo: o argumento da economia em infraestrutura só vale até o ponto em que a capacidade da infraestrutura não está esgotada e se torna necessário investir em sua ampliação. Esse argumento é bastante claro com a infraestrutura viária: baixa 
densidade e espraiamento geram custos com a ampliação da rede viária, mas densidade alta demais (e um modelo de mobilidade baseado no carro) também gera esgotamento da infraestrutura, com o agravante de que nem sempre é possível (e desejável) investir na ampliação de sua capacidade.

$\mathrm{O}$ argumento da preservação do meio ambiente natural também tem uma validade restrita, pois adianta muito pouco em termos práticos, em ganho de qualidade de vida no dia a dia do citadino, se pensarmos apenas na preservação do meio ambiente. Isso pode fazer algum sentido numa visão global, em termos de balanço das emissões de carbono e de limitação do efeito estufa, mas a perda de cobertura vegetal dentro das cidades cria ilhas de calor, degrada a paisagem urbana e diminui ou torna pouco convidativas as áreas públicas de convívio. Se o adensamento for feito por intensa verticalização e/ou sem respeitar recuos e sem utilizar estratégias arquitetônicas como o pilotis, o impacto sobre o micro-clima piora com o obstáculo à ventilação. Além disso, perda de cobertura vegetal também leva a uma maior impermeabilização do solo, impactando a drenagem da água da chuva e levando aos costumeiros alagamentos que Campo Grande sofre em certas épocas durante o ano.

Sendo assim e considerando que a cidade quer torna-se sustentável, existem várias maneiras de adensar e, só temos investido em uma delas, a verticalização, e uma verticalização com certas características que acabam por diminuir os ganhos do adensamento e aumentar suas desvantagens. Adensamento e verticalização não são sinônimos. Paris e Barcelona têm densidades, seja em proporção de área construída, seja em número de habitantes por hectares, às vezes maiores do que a das áreas mais verticalizadas de diversas capitais brasileiras. E nem sempre o adensamento estimula a vitalidade urbana $\mathrm{e}$ a segurança pela presença de pessoas na rua. Ele é uma pré-condição, mas não condição suficiente.

Gradativamente, com a falta de controle do poder público, o comércio tem se agrupado em shoppings e hipermercados e a cidade, com seu desenvolvimento urbano planejado pelas construtoras, tem repetido um dos erros de Brasília: a aglomeração de certos tipos de atividade em "pólos" Tudo isso estimula ainda mais o deslocamento motorizado, degradando a qualidade ambiental das ruas, tornando as perigosas e criando um círculo vicioso a favor do carro. Finalizando, as leis urbanísticas, ao invés de levarem em consideração o esgotamento das ruas antes de permitir novos prédios, estimulam a construção de mais vagas de garagem e o uso do automóvel.

O adensamento, como forma de multiplicar em área construída a área inicial do terreno, também é um fator de forte valorização do solo e, por consequência, de pressão especulativa sobre lotes ainda não explorados ao seu máximo potencial econômico. Costuma-se argumentar a favor de pouca regulação do mercado imobiliário a partir da ideia de que o livre atendimento das demandas e um forte adensamento permitirá garantir uma oferta alta o suficiente para empurrar os preços para baixo. Mas essa valorização do solo com o aumento do adensamento acaba por encarecer as unidades produzidas e diminuir o efeito do aumento da oferta. Além disso, cria pressão especulativa sobre as casas que ainda resistem numa determinada área e tornam áreas ocupadas por comunidades de baixa renda um alvo do capital imobiliário. $O$ efeito colateral disso é a gradual expulsão, violenta ou pela força do encarecimento do custo de vida, da população de baixa renda de áreas centrais e próximas aos bairros mais "nobres". Isso cria um adensamento só entre os mais ricos e um espraiamento e periferização da pobreza, o que, além da óbvia segregação entre classes, cria problemas de mobilidade maiores justo para a parcela menos privilegiada da população e as grandes distâncias a percorrer diariamente .

Para Mascaró (1989) as cidades espalhadas e fragmentadas (caso de Campo Grande) têm seus problemas e pode ocorrer como consequência de duas questões: baixa densidade urbana resultante de lotes com áreas grandes e falta de continuidade da malha urbana, chamada de leapfrogging ou vazios urbanos. Para eles, nesses casos, "enquanto o custo da terra tende a ser baixo, o padrão de desenvolvimento é economicamente insuficiente, tornando-o indesejável e sendo objeto de estudos frequentes nas últimas décadas".

Mascaró reforçam que a falta de continuidade da malha urbana, resultante de um grande número de vazios urbanos dentro da área urbanizada, típica de Campo Grande, provoca densidades muito baixas, alimentando os custos de serviços públicos e de infraestrutura urbana para cima.

A média dos parcelamentos após a Lei federal 6.766/1979 é de 30 lotes por hectare (ou em torno de 100 hab/ha, se todos estiverem ocupados), com apenas uma edificação uniresidencial por lote, mas, por força dos vazios urbanos, a densidade média encontrada para as cidades de porte médio é de apenas 40 pessoas por hectare (Campo Grande tem menos de 30 hab/ha).

Para Mascaró e Mascaró, a densidade mais adequada varia entre 300 e 350 pessoas por hectare, e que podemos considerar o mínimo de 40 pessoas por hectare, para ser economicamente aceitável. Essas densidades, para eles, permitem ainda se ter uma boa qualidade ambiental da cidade e são, também, eficientes do ponto de vista energético ao aproveitar os aspectos favoráveis do clima local.

A densidade urbana quando se mistura o uso residencial e o comercial e de serviços provoca um impacto visual gigantesco, com a imagem de milhares de edifícios, temos de nos precaver com relação aos problemas urbanos dele decorrentes. O reconhecimento do espaço residencial, em que se desenvolve 
grande parte do cotidiano dos moradores de uma cidade, como tema central na questão da qualidade do espaço construído, é essencial nessa discussão. Na conformação do espaço residencial identificam-se três grandes componentes, ou campos de análise: a moradia propriamente dita; a infraestrutura, serviços e equipamentos urbanos; e o entorno ou paisagem. As principais variáveis de análise de cada componente podem ser descritas como segue (Scussel e Suttler, 2010):

- Moradia: tamanho/densidade de ocupação; funcionalidade; material e técnica construtiva; tipo arquitetônico; estado de conservação; conforto térmico;

- Infraestrutura, serviços e equipamentos urbanos: água: tipo de abastecimento/tratamento; esgoto: coleta/destino/tratamento; lixo: coleta/destino; luz e telefone; transportes; escola; posto de saúde; áreas verdes, praças e parques; espaços culturais: museus/bibliotecas/teatro; comércio; e

- Entorno: ambiente construído - patrimônio arquitetônico; arborização; trânsito; ruído; ventilação; insolação - exposição solar; segurança; vizinhança.

Entretanto, o que se vê nas conclusões das pesquisas realizadas, é uma divisão entre cidades mais compactas, com centros fortes e boas condições de transporte público e cidades multinucleares, teoricamente capazes de servir tanto ao transporte público como ao automotor privado. Ainda vale a pena reforçar o tipo de clima, a situação socioeconômica ou a cultura local.

Nos anos 1980 havia as primeiras propostas de construção de indicadores de sustentabilidade, para contribuir nas tomadas de decisões dos atores envolvidos tanto da esfera pública quanto da privada, mas as concepções e conceitos diferentes tornou-se complexo e a elaboração de indicadores na época. Atualmente hpa diversos modelos internacionais e nacionais sobre sustentabilidade nas cidades e construção. Como a recém aprovada NBR ISSO 37120:2017 para cidades sustentáveis.

\subsection{Parâmetros para o IDVS}

A partir dos estudos dos conceitos de cidade sustentável, compacta para a construção dos indicadores, alguns parâmetros foram considerados:

- Densidade qualificada, planejada urbanisticamente para cada contexto, de acordo com os diversos usos adequados, não conflitantes com as necessidades dos usuários, procurando a valorização do uso misto na escala intraurbana e que favoreça a população local estar próxima de suas necessidades urbanas básicas.

- Necessidades urbanas básicas do morador que é tudo aquilo que lhe faz falta no seu dia a dia usual: serviços e equipamentos urbanos básicos, espaços verdes, comércio e local e acesso ao sistema de transporte coletivo e devem, em núcleos compactos, ser acessíveis em, no máximo, 10 minutos a pé ou estar em distância máxima de sua moradia de 1.000 metros.

- Interação social, a população residente possui mais oportunidades, bem como uma melhor sensação de segurança pública, uma vez que se estabelece melhor o senso de comunidade (proximidade, mix de usos, e calçadas e espaços de uso coletivo).

- Mobilidade urbana, o imenso gargalo do déficit habitacional e a falta de diversidade socioterritorial nas grandes cidades brasileiras devem ser resolvidos com novos modelos de desenvolvimento urbano sustentável, incorporando processos que promovam moradias em áreas mais densas e compactas, com mistura de usos, próximas ao sistema de mobilidade, que ofereçam diversidade tipológica e promovam a vida urbana mais inclusa e menos isolada.

- Crescimento ordenado do território como pré-requisito básico para uma cidade mais sustentável. Compondo este tema, têm-se os parâmetros que o definem como os elementos de desenho urbano, que formam a adequação urbanística do território (formas de implantação adequada, adequações visual, paisagística e sonora, preexistências a manter, geografia a respeitar), o nível de compacidade do território (onde compactar mais a cidade e com quais índices) e densidade qualificada (adensar com parâmetros de uso misto adequados a cada trecho da cidade), os eixos de crescimento e desenvolvimento urbano nas escalas regional e macrometropolitana, os graus de renovação urbana, o desejável crescimento territorial integrado ao sistema de mobilidade e os níveis de uso misto e uso coletivo do território. (Leite, 2012).

Neste aspecto é possível perceber que a cidade sustentável não pode ser implantada sem a junção da busca de uma densidade urbana ideal e da verticalização, conceitos anteriormente trabalhados.

Por fim e após essas discussões teóricas aqui apresentadas podemos construir um quadro de Pontos Positivos e Negativos da Densidade e da Verticalidade Urbana: 
Tabela 2 - Pontos Positivos e Negativos da densidade e verticalidade urbana

\begin{tabular}{|c|c|}
\hline Pontos Positivos & Pontos Negativos \\
\hline Aumento da arrecadação de impostos por hectare; & Provoca congestionamentos em geral; \\
\hline Menor desmatamento por hectare; & Promove a perda da paisagem urbana; \\
\hline $\begin{array}{l}\text { Concentração de toda a infraestrutura de suporte } \\
\text { seja dos sistemas de transporte, comunicação, } \\
\text { água, esgoto, energia ou dados seja dos sistemas } \\
\text { sociais de educação, saúde, cultura, esporte e lazer; }\end{array}$ & Aumenta os ruídos urbanos; \\
\hline Aumento da permeabilidade do solo por hectare; & $\begin{array}{l}\text { Reparos e manutenção demorados podem } \\
\text { prejudicar o coletivo; }\end{array}$ \\
\hline $\begin{array}{l}\text { Aumento da disponibilidade de área verde por } \\
\text { habitante; }\end{array}$ & $\begin{array}{l}\text { Conforto térmico tende a piorar provocado por ilhas } \\
\text { de calor; }\end{array}$ \\
\hline Aumento da mobilidade a pé e de bicicleta; & Aumento da poluição ambiental; \\
\hline Aumento da segurança comunitária; & $\begin{array}{l}\text { Pode piorar o atendimento dos serviços públicos } \\
\text { essenciais e dos serviços privados de consumo; }\end{array}$ \\
\hline Compacidade dos bairros; & $\begin{array}{l}\text { Perda da memória urbana e do patrimônio cultural } \\
\text { do lugar; }\end{array}$ \\
\hline Ocupação dos vazios urbanos; & Perda de privacidade do cidadão; \\
\hline Criação de novas centralidades urbanas; & \multirow{4}{*}{$\begin{array}{l}\text { Insegurança no entorno, por meio de ruas somente } \\
\text { com muros altos sem fachadas ativas. }\end{array}$} \\
\hline Permite criar fachadas ativas; & \\
\hline $\begin{array}{l}\text { Pode baratear os custos dos serviços essenciais, } \\
\text { especialmente transporte coletivo; }\end{array}$ & \\
\hline Melhoria na oferta dos serviços públicos em geral. & \\
\hline
\end{tabular}

Elaborado pelos autores, 2018.

\subsection{Densidade, Verticalidade e Sustentabilidade em Campo Grande}

A cidade de Campo Grande, capital de Mato Grosso do Sul, Brasil, iniciou sua ocupação na confluência dos Córregos Prosa e Segredo no final do século XIX, teve um processo de urbanização local rápido e intenso desde o inicio da sua ocupação. Hoje possui uma área de $8.092,951 \mathrm{Km}^{2} \mathrm{com} 786.797$ habitantes (IBGE, 2010), sendo que aproximadamente $99 \%$ da população estão na área urbana. O processo de urbanização intenso provocou extensas áreas vazias, ao mesmo tempo concentração de edifícios verticais em algumas regiões e condomínios habitacionais horizontal fechados, principalmente localizados na parte mais periférica da cidade.

A cidade tem como características bem marcantes, a falta de continuidade do tecido urbano, devido ao grande número de vazios urbanos, o que provoca densidades muito baixas, aumentando os custos de serviços públicos e de infraestrutura urbana, e pouca verticalidade, que iniciou nos anos 40 mas foi em 1977 que o plano diretor da cidade indicou várias áreas na cidade que teriam potencial para verticalizar, surgindo áreas possíveis para mais de 12 pavimentos para a construção e novas áreas para edificar. Atualmente Campo Grande possui a densidade de abaixo de 30hab/ha e cerca de 910 edifícios verticais com mais de 03 pavimentos. 


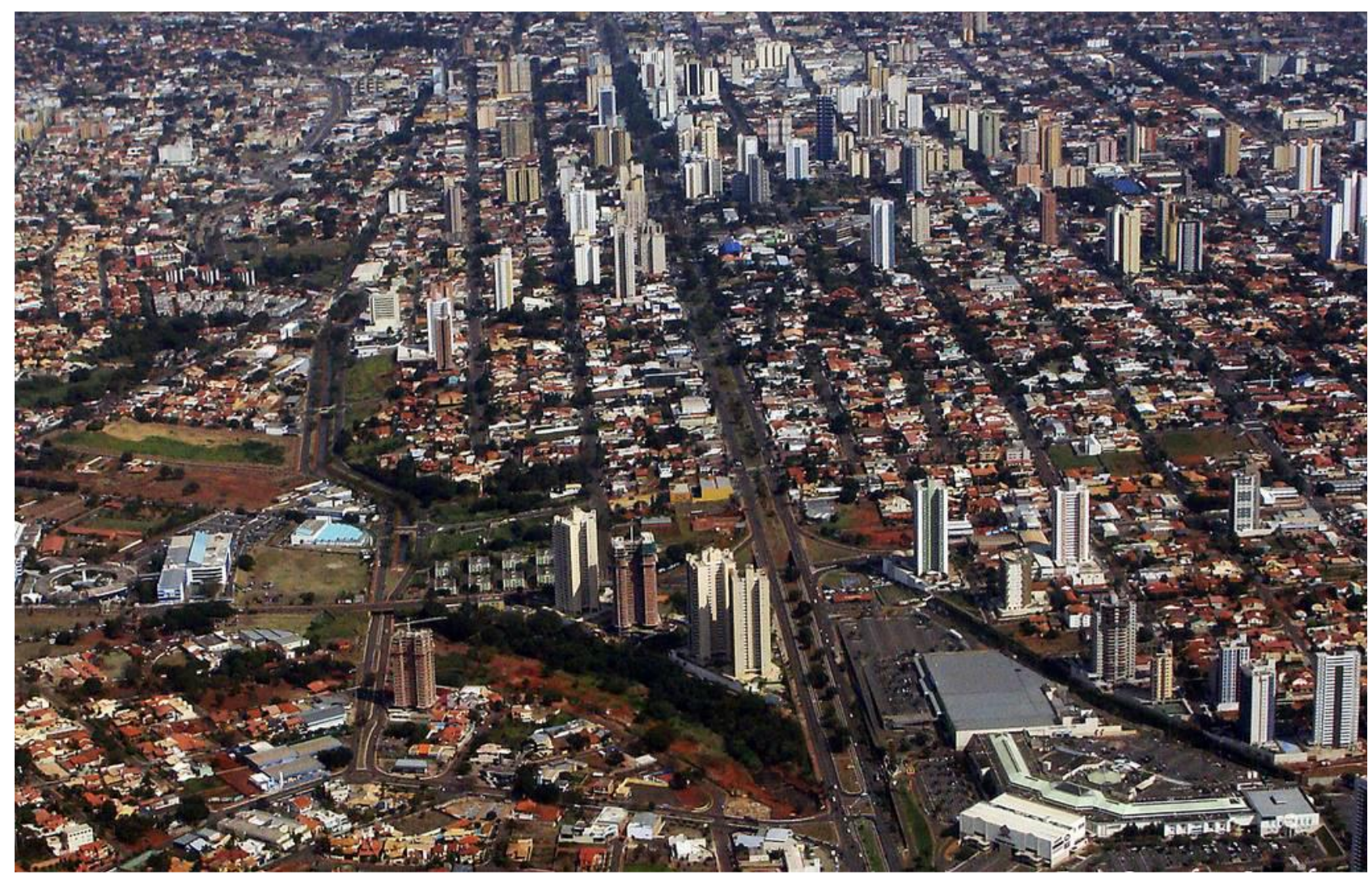

\section{Figura 2- Campo Grande}

(Observatório de Arquitetura e Urbanismo / UFMS, 2016)

Foi no ano de 1986 que o Conselho Nacional de Meio Ambiente publicou a Resolução CONAMA n. 001/86 que tratava das definições, critérios e normas para análise de Impacto Ambiental no país,e a cidade de Campo Grande se inseriu no processo de discussão ambiental e da sustentabilidade. Com a aprovação da Lei municipal n. 2.567/1988 que determinava a Lei de Ordenamento de Uso e Ocupação do Solo urbano que surgiam os primeiros arcabouços legais e que se transformaram e evoluíram ao longo de todo esse período, até os dias atuais. Essa lei era muito inovadora em questões ambientais urbanas. Ela estabelecia critérios para licenciamento de todas as atividades poluidoras ou impactantes, instituiu a proteção ao meio ambiente, com a autorização para criação de Unidades Conservadoras e a aprovação do Estudo de Impacto Ambiental (EIA-RIMA) previsto na legislação federal.

As últimas modificações institucionais ocorreram com a definição dos papéis do Instituto de Planejamento Urbano (PLANURB) e da Secretaria de Meio Ambiente e Desenvolvimento Urbano (SEMADUR) no tema meio ambiente e sustentabilidade, a partir no ano 2000.

\section{METODOLOGIA DO INDICADOR}

A partir dos Pontos Positivos apresentados anteriormente, listou as potencialidades e as condicionantes (tabelas 3 e 4), dos três eixos de estudo desse trabalho (densidade, verticalização e sustentabilidade urbana), que serão aspectos norteadores para a construção do Indicador de Densidade, Verticalidade e Sustentabilidade Urbana (IDVS) 
Tabela 3- Potencialidade dos eixos do estudo

\begin{tabular}{|l|l|l|}
\hline \multicolumn{1}{|c|}{ Densidade } & \multicolumn{1}{c|}{ Verticalização } & \multicolumn{1}{c|}{ Sustentabilidade Urbana } \\
\hline $\begin{array}{l}\text { Eficiência na de } \\
\text { infraestrutura }\end{array}$ & Concentração de investimentos & Infraestrutura \\
\hline Uso eficiente da terra & Geração de emprego e renda & Governança \\
\hline Vitalidade urbana & $\begin{array}{l}\text { Aquecimento do mercado } \\
\text { imobiliário }\end{array}$ & Mobilidade \\
\hline Geração de receitas & $\begin{array}{l}\text { Conectividade com atividades } \\
\text { diárias }\end{array}$ & Moradia \\
\hline Maior controle social & Concentração de usos ordenamento \\
\hline Economias de escala & $\begin{array}{l}\text { Valorização do uso do solo e } \\
\text { infraestrutura }\end{array}$ & Questões ambientais \\
\hline $\begin{array}{l}\text { Facilidade de acesso aos } \\
\text { consumidores }\end{array}$ & & Segurança \\
\hline $\begin{array}{l}\text { Maior acessibilidade às atividades } \\
\text { diárias }\end{array}$ & & Serviços e equipamentos \\
\hline Miscigenação de usos & & \\
\hline Serviços públicos econômicos & & \\
\hline Transporte público eficiente & & \\
\hline $\begin{array}{l}\text { Utilização de parques } \\
\text { equipamentos por maior número } \\
\text { de pessoas }\end{array}$ & & \\
\hline
\end{tabular}

(Elaborado pelos autores)

Tabela 4 - Condicionantes dos eixos do estudo

\begin{tabular}{|c|c|c|}
\hline \multicolumn{3}{|c|}{ CONDICIONANTES } \\
\hline Densidade & Verticalização & Sustentabilidade Urbana \\
\hline $\begin{array}{l}\text { Layout dos assentamentos e } \\
\text { equilíbrio entre público e privado }\end{array}$ & Questões da modernidade & $\begin{array}{l}\text { Necessidades urbanas básicas } \\
\text { para a população }\end{array}$ \\
\hline Disponibilidade de solo urbano & Técnica, espaço e verticalização & Acesso à informação disponível \\
\hline Tipologia habitacional & $\begin{array}{l}\text { Impactos na estrutura interna da } \\
\text { cidade }\end{array}$ & Interação social \\
\hline Quantidade de empreendimentos & $\begin{array}{l}\text { Legislação urbana para a } \\
\text { verticalização }\end{array}$ & $\begin{array}{l}\text { Politica habitacional e diversidade } \\
\text { socioterritorial }\end{array}$ \\
\hline Tamanho e forma dos edifícios & $\begin{array}{lll}\text { Incorporação } & \text { imobiliária } & \text { e } \\
\text { verticalização } & & \\
\end{array}$ & $\begin{array}{ll}\text { Unidades } & \text { habitacionais } \\
\text { produzidas } & \\
\end{array}$ \\
\hline Localização das unidades & Etapas da verticalização & $\begin{array}{l}\text { Crescimento ordenado do } \\
\text { território }\end{array}$ \\
\hline Legislação e planejamento & & Densidade qualificada \\
\hline $\begin{array}{l}\text { Proximidades de entorno de } \\
\text { atividades }\end{array}$ & & $\begin{array}{lcr}\text { Qualidade } & \text { e } & \text { localização dos } \\
\text { serviços } & \text { e } & \text { equipamentos } \\
\text { disponíveis } & & \\
\end{array}$ \\
\hline Tamanho e dimensão do lote & & \\
\hline Concentração de infraestruturas & & \\
\hline Planejamento urbano & & \\
\hline $\begin{array}{l}\text { Área total das unidades } \\
\text { habitacionais }\end{array}$ & & \\
\hline
\end{tabular}

Elaborado pelos autores 


\subsection{O IDVS}

Para efeitos desse estudo e considerando essas variáveis acima, a equipe, com o assessoramento do Professor Leandro Sauer da UFMS, preparou uma LISTA DE ITENS DE BENS E SERVIÇOS DA SUSTENTABILIDADE URBANA.

Para a definição da lista de bens e serviços de natureza essencial para uma comunidade, foram tomadas como base para a construção de 10 (dez) itens importantes para enquadramento de condomínios horizontais e verticais em Campo Grande/MS, com a finalidade de promover uma qualificação e podermos construir o INDICADOR IDVS.

Os critérios usados para elaboração dessa lista considerou itens que estejam DENTRO DO CONDOMÍNIO, ou seja, que pertençam aos limites internos da propriedade e que sejam de uso exclusivo de seus moradores e itens que estejam FORA DO CONDOMíNIO, ou seja,que além de serem do uso dos moradores também são das demais pessoas do bairro e da cidade.

Lista de bens e serviços dentro do condomínio:

1. Ter densidade líquida menor que $300 \mathrm{hab} / \mathrm{ha}$;

2. Ter um sistema construtivo que utiliza técnicas sustentáveis²;

3. Possuir garagem de bicicletas além dos automóveis;

4. Ter área permeável reservada e controlada maior que $12,5 \%$ do terreno ${ }^{3}$;

5. Fazer reuso de águas servidas ${ }^{4}$;

6. Ter coleta seletiva de lixo orientada e incentivada;

7. Fazer armazenagem de água de chuva;

8. Utilizar placas solares em áreas comuns e privativas;

9. Ter vagas de visitantes do condomínio (externa/ interna);

10. Possuir Área de lazer completa para os moradores;

Lista de bens e serviços fora do condomínio:

1. O edifício possuir calçada acessível;

2. Entorno com iluminação e arborização adequadas;

3. Ter fachada ativa ${ }^{6}$

4. Ter um entorno/vizinhança habitada e adensada;

5. Ter entorno com atividades comerciais/serviços adensado;

6. Ter comércio local (mercado, padaria, farmácia) próximo (300 metros de raio);

7. Ter praças, parques e ou pistas de caminhada no entorno (300 metros de raio);

8. Ter Ponto de ônibus/ transporte coletivo próximo (500 metros de raio);

9. Ter Unidades de saúde e creches ou escola pública ou privada (500 metros de raio);

10. Ter Unidades de segurança pública (500 metros de raio).

A partir dessas variáveis, foi elaborado um questionário (conforme as figuras abaixo) e consultado 15 especialistas dentre professores, pesquisadores, arquitetos e urbanistas, construtores, empresários e entidades locais, cada um respondeu as suas prioridades nas combinações de itens desejáveis. $O$ questionário corresponde a combinação simples entre os itens, posteriormente quantificando e somando as respostas de cada item de preferência, atribuindo pesos diferentes para a qualificação do empreendimento.

\footnotetext{
2 Técnicas construtivas que garantem racionalização e a criação de obras mais limpas e ambientalmente corretas, seja por seus métodos operacionais ou pelos materiais que emprega. Viabilizam construções com produtividade elevada, custos mais acessíveis e alta qualidade.

${ }^{3} \mathrm{Na}$ cidade de Campo Grande, a Lei de Uso e Ocupação do solo exige que dentro dos lotes 12,5\% de área permeável

${ }^{4}$ Reaproveitamento da água, o processo pelo qual a água, tratada ou não, é reutilizada pelo homem na mesma função, ou em outra atividade humana diferente da primeira.

${ }^{5}$ Atividades para todas as faixas etárias dentro do condomínio, com equipamentos adequados.
}

\footnotetext{
${ }^{6}$ Fachada ativa corresponde à ocupação da fachada localizada no alinhamento de passeios públicos por uso não residencial com acesso aberto à população e abertura para o logradouro
} 


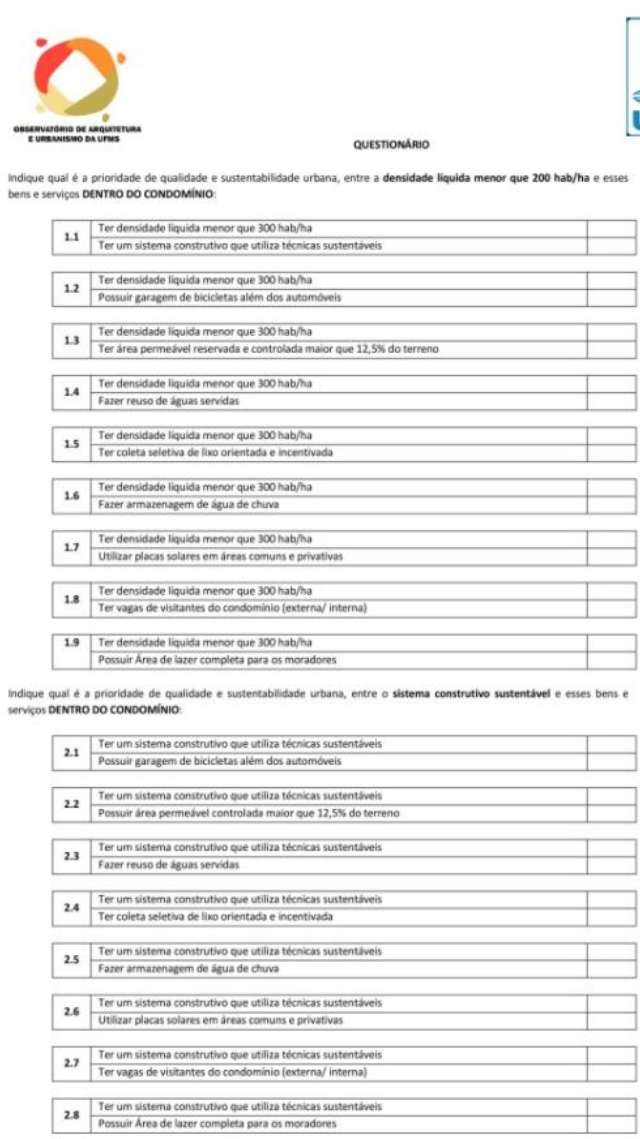

\section{0}

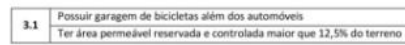

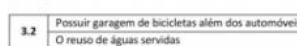

32 Oresuo de iguas sended

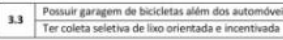

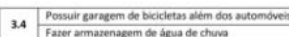

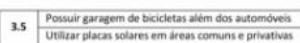

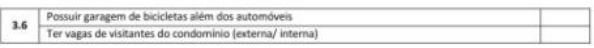

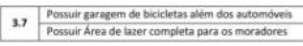

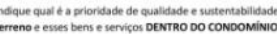

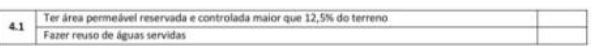

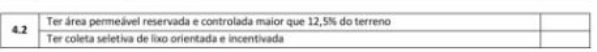

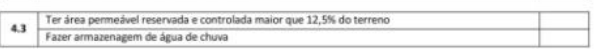

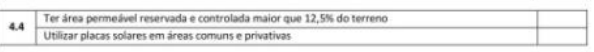

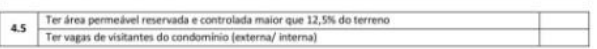

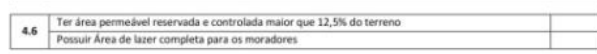

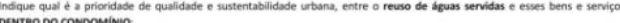

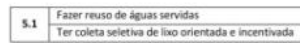

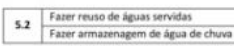

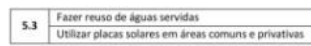

\section{0}

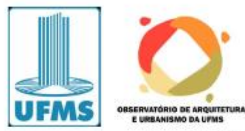

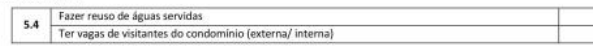

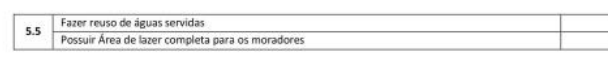

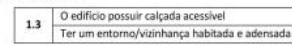

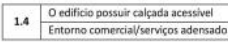

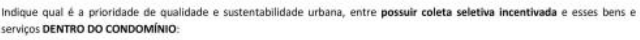

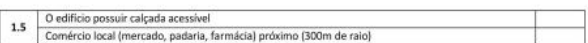

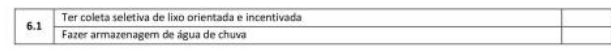

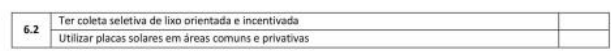

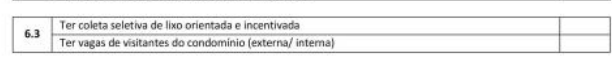

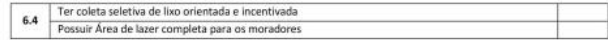

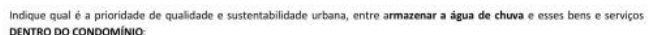

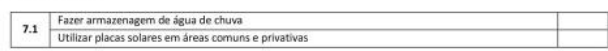

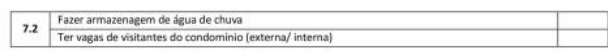

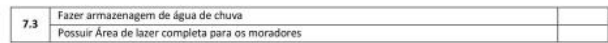

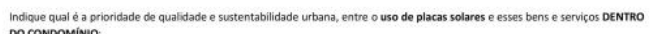

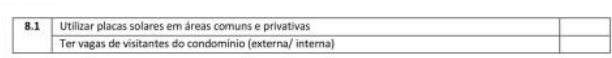

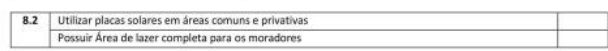

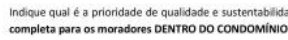

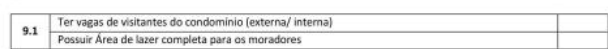

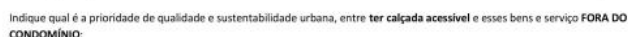

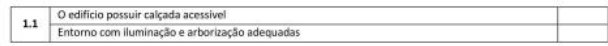

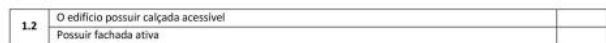

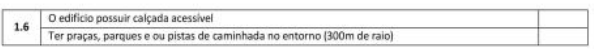

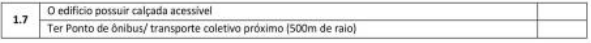

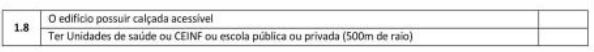

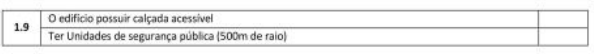

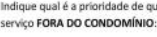

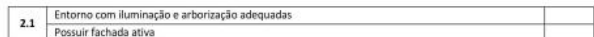

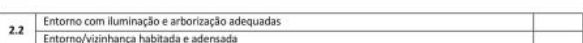

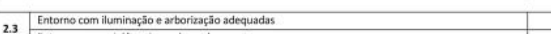

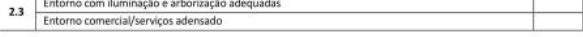

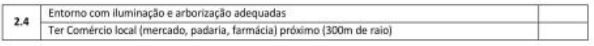

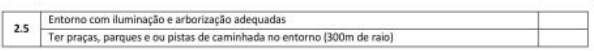

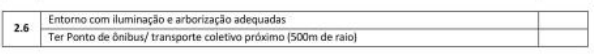

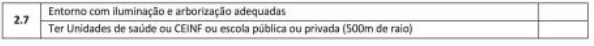

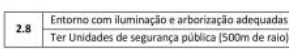

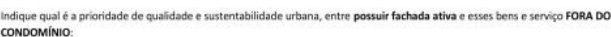

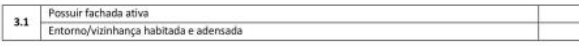

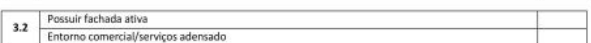




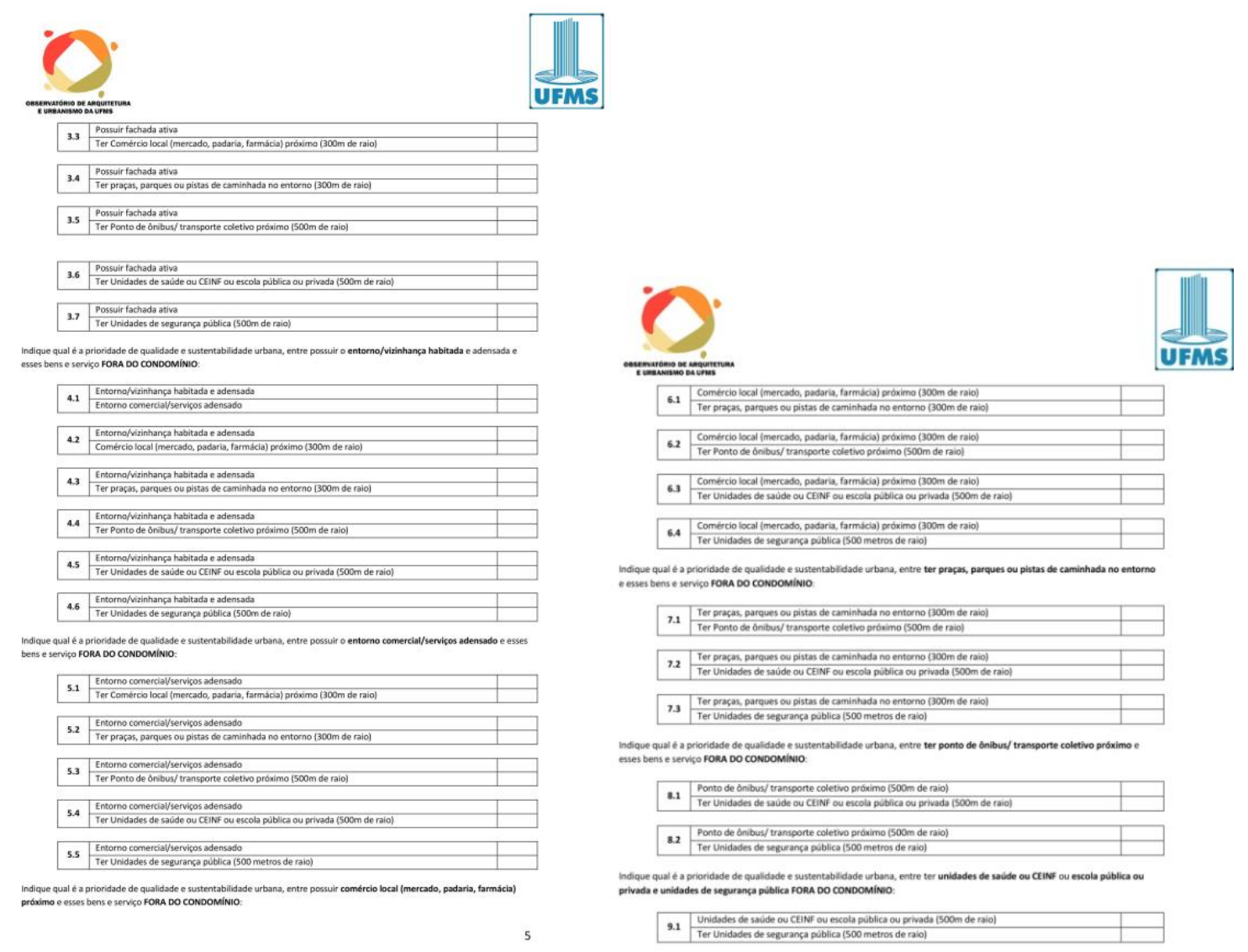

Figuras 3, 4, 5, 6, 7 e 8 - Questionário para elaboração do IDVS (Observatório de Arquitetura e Urbanismo, 2017)

Esse questionário resultou em uma sequência de prioridades, que conforme a quantidade dentre os elementos escolhidos, foi atribuído pesos diferentes entre os itens com o total igual a 1,000 (um), conforme a tabela abaixo, sendo que quanto mais próximo de 1,000 (um) mais favorável se encontra o condomínio na relação entre densidade $x$ verticalidade $x$ sustentabilidade.

Tabela 5 - Indicadores para dentro do condomínio e peso de cada item

\begin{tabular}{|l|l|l|}
\hline \multicolumn{1}{|c|}{ DENTRO DO CONDOMINIO } \\
\hline \multicolumn{1}{|c|}{ ITEM } & \multicolumn{1}{|c|}{ PESO } \\
\hline 01 & Densidade líquida menor que 300 hab/ha & 0,080 \\
\hline 02 & Ter um sistema construtivo que utiliza técnicas sustentáveis & 0,093 \\
\hline 03 & Possuir garagem de bicicletas além dos automóveis & 0,049 \\
\hline 04 & Ter área permeável reservada e controlada maior que 12,5\% do terreno & 0,104 \\
\hline 05 & Fazer reuso de águas servidas & 0,114 \\
\hline 06 & Ter coleta seletiva de lixo orientada e incentivada & 0,132 \\
\hline 07 & Fazer armazenagem de água de chuva & 0,150 \\
\hline 08 & Utilizar placas solares em áreas comuns e privativas & 0,119 \\
\hline 09 & Ter vagas de visitantes do condomínio (externa/ interna) & 0,074 \\
\hline 10 & Possuir Área de lazer completa para os moradores & 0,086 \\
\hline TOTAL & & 1,000 \\
\hline
\end{tabular}

(Elaborado pelos autores a partir dos dados do Observatório de Arquitetura e Urbanismo/ UFMS, 2017)

Tabela 5 - Indicadores para fora do condomínio e peso de cada item

\begin{tabular}{|l|l|c|}
\hline \multicolumn{1}{|c|}{ FORA DO CONDOMINIO } \\
\hline \multicolumn{1}{|c|}{ ITEM } & \multicolumn{1}{|c|}{ PESO } \\
\hline 01 & O edifício possuir calçada acessível; & 0,098 \\
\hline 02 & Entorno com iluminação e arborização adequadas; & 0,104 \\
\hline 03 & Ter fachada ativa & 0,047 \\
\hline 04 & Ter um entorno/vizinhança habitada e adensada; & 0,130 \\
\hline 05 & Ter entorno com atividades comerciais/serviços adensado; & 0,059 \\
\hline
\end{tabular}




\begin{tabular}{|l|l|l|}
\hline 06 & Ter comércio local (mercado, padaria, farmácia) próximo (300 metros de raio); & 0,119 \\
\hline 07 & Ter praças, parques e ou pistas de caminhada no entorno (300 metros de raio); & 0,123 \\
\hline 08 & Ter Ponto de ônibus/ transporte coletivo próximo (500 metros de raio); & 0,138 \\
\hline 09 & Ter Unidades de saúde, creches ou escola pública ou privada (500 metros de raio); & 0,101 \\
\hline 10 & Ter Unidades de segurança pública (500 metros de raio) & 0,081 \\
\hline TOTAL & & 1,000 \\
\hline
\end{tabular}

(Elaborado pelos autores a partir dos dados do Observatório de Arquitetura e Urbanismo/ UFMS, 2017)

\section{CONSIDERAÇÕES FINAIS}

O resultado dos indicadores com elevados pontos favoráveis se encontram em pares com os conceitos ligados à diversidade, inclusão, uso misto, etc. corroborando com as teorias dos autores utilizados como parâmetros conceituais do estudo: Jacobs, Mascaró, Aciolly, Villaça, etc.

Analisando os resultados por ordem de prioridade, os indicadores com peso maior para "dentro do condomínio" são, por ordem: fazer armazenagem de água da chuva; ter coleta seletiva de lixo orientada e incentivada; utilizar placas solares em áreas comuns e privativas; fazer reuso das águas servidas; e ter área permeável reservada e controlada maior que $12,5 \%$ do terreno. (Tabela 6 )

Tabela 6 - Indicadores para dentro do condomínio e peso de cada item - análise das prioridades

\begin{tabular}{|l|l|l|}
\hline \multicolumn{2}{|l|}{ DENTRO DO CONDOMINIO } & PESO \\
\hline & ITEM & 0,080 \\
\hline 01 & Densidade líquida menor que 300 hab/ha & 0,093 \\
\hline 02 & Ter um sistema construtivo que utiliza técnicas sustentáveis & 0,049 \\
\hline 03 & Possuir garagem de bicicletas além dos automóveis & 0,104 \\
\hline 04 & Ter área permeável reservada e controlada maior que 12,5\% do terreno & 0,114 \\
\hline 05 & Fazer reuso de águas servidas & 0,132 \\
\hline 06 & Ter coleta seletiva de lixo orientada e incentivada & 0,150 \\
\hline 07 & Fazer armazenagem de água de chuva & 0,119 \\
\hline 08 & Utilizar placas solares em áreas comuns e privativas & 0,074 \\
\hline 09 & Ter vagas de visitantes do condomínio (externa/ interna) & 0,086 \\
\hline 10 & Possuir Área de lazer completa para os moradores & 1,000 \\
\hline TOTAL & &
\end{tabular}

(Elaborado pelos autores a partir dos dados do Observatório de Arquitetura e Urbanismo/ UFMS, 2017)

Os resultados dos indicadores "fora do condomínio", os pontos mais favoráveis e de prioridade dentro do indicador foram, em ordem de prioridade: ter ponto de ônibus/transporte coletivo próximo (500 metros de raio); ter um entorno/vizinhança habitada e adensada; ter praças, parques e ou pistas de caminhada no entorno (300 metros de raio); ter comércio local (mercado, padaria, farmácia) próximo (300 metros de raio); e entorno com iluminação e arborização adequadas. (Tabela 7)

Tabela 7 - Indicadores para fora do condomínio e peso de cada item - análise das prioridades

\begin{tabular}{|l|l|c|}
\hline \multicolumn{1}{|c|}{ FORA DO CONDOMINIO } & PESO \\
\hline & \multicolumn{1}{|c|}{ ITEM } & 0,098 \\
\hline 01 & O edifício possuir calçada acessível; & 0,104 \\
\hline 02 & Entorno com iluminação e arborização adequadas; & 0,047 \\
\hline 03 & Ter fachada ativa & 0,130 \\
\hline 04 & Ter um entorno/vizinhança habitada e adensada; & 0,059 \\
\hline 05 & Ter entorno com atividades comerciais/serviços adensado; & 0,119 \\
\hline 06 & Ter comércio local (mercado, padaria, farmácia) próximo (300 metros de raio); & 0,123 \\
\hline 07 & Ter praças, parques e ou pistas de caminhada no entorno (300 metros de raio); & 0,138 \\
\hline 08 & Ter Ponto de ônibus/ transporte coletivo próximo (500 metros de raio); & 0,101 \\
\hline 09 & Ter Unidades de saúde, creches ou escola pública ou privada (500 metros de raio); & 0,081 \\
\hline 10 & Ter Unidades de segurança pública (500 metros de raio) & 1,000 \\
\hline TOTAL & &
\end{tabular}

(Elaborado pelos autores a partir dos dados do Observatório de Arquitetura e Urbanismo/ UFMS, 2017) 
Dentro deste estudo, os resultados encontrados podem servir como auxílio no momento do planejamento de cidades e implantação de condomínios dentro da área urbana, servindo como um indicador de prioridades para que a implantação destes condomínios possuam uma base de densidade, verticalidade e sustentabilidade. Como também, contribui para a compreensão das formas de produção e reprodução da vida urbana. Um indicador simples, quantificável e comunicável.

\section{BIBLIOGRAFIA}

ACIOLLY, C. DAVIDSON, F. (1998). Densidade Urbana: um instrumento de planejamento e gestão urbana. Rio de Janeiro: Mandad

JACOBS, J. (2000). Morte e vida nas grandes cidades. São Paulo: Martins Fontes.

LEITE, C. (2012). Cidades Sustentáveis, Cidades Inteligentes. Desenvolvimento sustentável num planeta urbano.

MASCARÓ, J. L.; YOSHINAGA, M. (2005). Infraestrutura Urbana. Porto Alegre: L. Mascaró.

MASCARÓ, J L. (1989). Desenho urbano e custos da urbanização. Porto Alegre: DC Luzzatto.

PREFEITURA DE CAMPO GRANDE. Agência Municipal de Meio Ambiente e Planejamento Urbano PLANURB. (2017). Perfil Socioeconômico de Campo Grande. Campo Grande.

SCUSSEL, M. da C. B.; SATTLER. M. A. (2010). Cidades em (trans)formação: impacto da verticalização e densificação na qualidade do espaço residencial.Ambiente Construído, Porto Alegre, v. 10, n. 3, p. 137-150. VILLAÇA, F. (1998). Espaço Intra-Urbano no Brasil. São Paulo: Studio Nobel.

CISNEIROS, L. Qual o problema da verticalização?. Recife, 2014. Disponível em https://direitosurbanos.wordpress.com/ (consulta 28/02/2018).

OBSERVATÓRIO DE ARQUITETURA E URBANISMO DA UFMS. Relatório Final: Densidade, verticalidade e sustentabilidade em Campo Grande: UFMS, 2017. Disponível em www.observatorio.ufms.br (consulta 28/02/2017). 